\title{
Theophylline as a systemic anti-inflammatory agent: the need for its revival as a possible adjunctive treatment for "inflammaging"
}

\author{
Allen $\mathrm{SC}^{1,2 *}$ and Tiwari $\mathrm{D}^{1}$ \\ ${ }^{1}$ The Royal Bournemouth Hospital, Dorset, UK \\ ${ }^{2}$ Centre for Postgraduate Medical Research and Education, Bournemouth University, Dorset, UK
}

\section{Introduction}

There is a great clinical and social need to search for treatments that can effectively ameliorate the consequences of systemic inflammation, particularly in elderly people in a pre-frail or overtly frail condition. This includes taking opportunities for drug "discovery" research on a range of established drugs in common use that, in addition to their main licensed effects, have been shown to modulate or down-regulate inflammatory biochemical networks. In this commentary the authors will summarize the extant evidence with particular reference to theophylline, then make a case for systematized research into similar properties for other drugs such as statins and 4-aminoquinolones.

\section{Background}

The innate immune system in older people often exhibits different characteristics when compared to younger adults. It has been shown that established biochemical markers of inflammation, such as interleukin-1 (IL-1), interleukin-6 (IL-6) and tumor necrosis factor (TNF) are frequently 2-4 -fold higher in the plasma of older subjects, and become increasingly so with advancing age, especially in people older than 80 years, when compared to the levels in adults aged 20-60 years [1-3]. In one particularly well conducted study of healthy people there was a mean baseline plasma TNF concentration of $0.6 \mathrm{pg} / \mathrm{ml}$ in adults below the age of 30 years compared to a mean of $1.5 \mathrm{pg} / \mathrm{ml}$ in those above the age of 70 years [4]. This is part of the phenomenon that has been described as "inflammaging", a term that is gaining currency in the fields of geriatric medicine and the immunology of ageing [1]. In many individual patients this observation can be explained by clinically obvious co-morbid chronic inflammatory conditions such as chronic obstructive pulmonary disease (COPD) or rheumatoid arthritis (RA) [3]. Further, similar raised levels of biochemical indicators of inflammation are often found in elderly people with other disorders that re-set the innate immune network in a pro-inflammatory direction, examples being central obesity, atheromatous disease, and type 2 diabetes [57]. Chronically raised pro-inflammatory markers have been found in association with Alzheimer's disease (AD), a sedentary lifestyle, chronic renal disease and osteoarthritis [5,8-10]. Intriguingly, some well elderly people have raised baseline chemical inflammatory markers that appear to have no apparent pathological cause, and age itself appears to be accompanied by an augmented baseline inflammatory state $[11,12]$. Healthy young adult volunteers were found to have mean blood C-reactive protein (CRP) levels of $0.9 \mathrm{mcg} / \mathrm{ml}$ compared to $3.0 \mathrm{mcg} / \mathrm{ml}$ in healthy people over the age of 65 [11]. IL-6 and IL-1 appear to be significantly correlated with age [13]. These observations have clinic-pathological relevance because persisting low-amplitude inflammation is associated with higher all-cause mortality, reduced skeletal muscle strength, impaired instrumental function affecting activities of daily living and lower self-reported wellbeing and health status $[14,15]$. The measured plasma levels of inflammatory markers, such as CRP, IL-1, IL-6 and TNF vary between studies, depending on methodology, but the respective adverse outcomes were generally associated with 1.5 to 3 -fold elevation above those found in healthy age-matched controls. Another clinically important factor that has immediate relevance to the contention we are putting forward in this commentary is the persisting augmentation of the pro-inflammatory state that often fails to resolve, or resolves slowly and incompletely, after an acute inflammatory event. This is an important factor in the rate and completeness of observed returns to pre-event function and presents a ripe target for research into effective interventions [16-23].

It is probable that chronic disease progression in a range of pathological states is to some extent due to chronic inflammation and not just an indicator of it [19]. There is evidently a complex interactive relationship between cause and effect. As a case in point, the endothelial inflammation found in atheromatous vascular disease has been extensively studied and is often cited as typifying the interaction between inflammation, ageing changes and pathology [20]. In many elderly people, the inflammatory response to acute stimuli, such as infection or injury, resolves more slowly than it does in younger adults. The observed rises in TNF, IL-1 and IL-6 persist longer and the sequential rise in the anti-inflammatory cytokine interleukin-10 (IL-10) is delayed and of lower amplitude. This effect has been clearly demonstrated for pneumococcal and Gram-negative endotoxin antigens [21,22], with an approximately 2 -fold increase in the time to return to baseline in elderly older subjects, despite similar pro-inflammatory peak levels. This indicates that regulatory anti-inflammatory function is impaired and can consequently cause a delay in re-setting the normative baseline surveillance state of the innate immune system. It can be argued that this is a likely candidate for the slower post-acute clinical recovery and chronic low-level inflammation often seen in old age [24].

${ }^{\star}$ Correspondence to: SC Allen, Department of Medicine, Royal Bournemouth Hospital, Castle Lane East, Bournemouth, Dorset, BH3 7DG, UK, Tel: +44 1202 303626; Fax: +44 1202 704542; E-mail: stephen.allen@rbch.nhs.uk

Received: January 03, 2019; Accepted: January 10, 2019; Published: January 17, 2019 
Other mechanisms for chronic age-associated inflammation might contribute to "inflammaging", such as a reduction in anti-oxidant capacity and thereby greater oxidative stress. The pro-inflammatory effect of oxidative stress appears to be by stimulation of toll-like receptors on various immune cells. However, the evidence for cytokines having a central role in age-associated inflammation is now well established.

Systemic inflammation is closely associated with key components of frailty, including sarcopenia and cachexia [24]. The molecular mechanisms are clearly complex. Components of the innate immune systems, notably chemokines, the catecholamine-cortisol axis, complement reactions, interferons, immune cells and other somatic cells communicate with and influence each other in a non-linear manner best visualized as a network. A full description is beyond the scope of this commentary, but the authors have published detailed background elsewhere [24]. Effective interventions are consequently more likely to be those that cause corrective changes to the innate immune network, often referred to as immune modulation, and thereby reduce the inflammatory burden that contributes to frailty.

\section{Proposition}

Theophylline, a methyl-xanthine drug, has a long history as a treatment for asthma and COPD. In patients with COPD it was noted that positive outcomes, such as improved walking performance, were reported in patients treated with theophylline even when little or no measurable change was demonstrated by spirometry, or arterial blood gas tensions. Importantly, the effect was also observed at plasma levels well below $(<10 \mathrm{mg} / \mathrm{L})$ those associated with significant toxic effects [25]. Pertinently, the anti-inflammatory properties of theophylline at these low concentrations were shown to act not only locally on airways inflammation but also systemically [26,27]. The full mechanism whereby the anti-inflammatory properties of theophylline modulates innate immune chemistry remains only partially understood, and probably varies over time, and between individuals, according to the pathophysiological context. Theophylline reduced post-acute TNF and IL-1, and increases IL-10, by around 25-50 per cent. Similarly, in vivo exposure to comparable concentrations of pentoxifylline, also a methyl-xanthine, caused a progressive reduction in the production of pro-inflammatory IL-1, IL-6, IL- 8 and TNF of between 20 and 80 percent by harvested peripheral blood monocytes over 4 days [27]. This property appears to be mediated through an epigenetic mechanism that activates histone deacetylase-dependent gene switches toward a more anti-inflammatory phenotype [26-28]. Therefore, these effects appear to be due to theophylline-induced re-direction toward the antiinflammatory state in macrophages and other immune cells which have been shown to have several dose-dependent gene switches that up- and down-regulate various cytokines. Subjects with COPD treated with the addition of theophylline to a standard regimen had lower baseline CRP levels and better functional scores compared with control subjects. These effects have been described as immune "modulation". It appears that theophylline at typical therapeutic doses reduces inflammation without compromising the protective effect of an appropriate acute inflammatory response to infection. It has also been shown that a reduction in mortality occurs in patients with severe sepsis treated with theophylline in a critical care setting [29-41].

\section{A call for research}

We contend that a case can be made for further well conducted studies of the use of low-dose theophylline to modulate inflammation when it is inappropriately prolonged after stimuli such as sepsis, particularly in pre-frail or overtly frail older patients with clinical and laboratory features of extended inflammation. There might also be a role for the long-term use of theophylline to dampen chronic inflammation to reduce the progression from pre-frailty to established frailty. More specifically, the principal targets for further research should be placebo-controlled trials of low-concentration (5$10 \mathrm{mg} / \mathrm{L}$ ) theophylline, given orally, as adjunctive treatment in elderly patients recovering from sepsis or trauma, and to establish whether chronic low-grade inflammation, as measured by peripheral blood biochemical markers such as TNF and IL-1 can be modified and functional outcomes improved. In any such studies defined outcomes would need to include mortality, mobility scores, functional scores, return to independent living, measurements of muscle strength, cognition, wellbeing scores, and duration of hospital treatment.

We have used theophylline as an exemplar in this commentary. However, similar clinically translatable property discovery research needs to be conducted on other drugs with immune modulating characteristics, including but not exclusively, statins, 4-aminoquinolones, salicylates, beta-adrenergic blockers, thalidomide, metformin and monoclonal antibodies.

\section{References}

1. Franceschi C, Campisi J (2014) Chronic inflammation (inflammaging) and its potential contribution to age-associated diseases. J Gerontol A Biol Sci Med Sci 69 Suppl 1: S4-9. [Crossref]

2. Wener MH, Daum PR, McQuillan GM (2000) The in?uence of age, sex and race on the upper reference limit of serum C-reactive protein concentration. J Rheumatol 27: 2351-2359.

3. Chung HY, Cesari M, Anton S, Marzetti E, Giovannini S, et al. (2009) Molecular in?ammation: Underpinnings of aging and age-related diseases. Ageing Res Rev 8: $18-30$.

4. Brüünsgaard H, Pedersen BK (2003) Age-related inflammatory cytokines and disease. Immunol Allergy Clin North Am 23: 15-39. [Crossref]

5. Caspersen CJ, Pereira MA, Curran KM (2000) Changes in physical activity patterns in the United States, by sex and cross-sectional age. Med Sci Sports Exerc 32: 1601-1609.

6. Driver JA, Djoussé L, Logroscino G, Gaziano JM, Kurth T (2008) Incidence of cardiovascular disease and cancer in advanced age: prospective cohort study. BMJ 337: a2467. [Crossref]

7. Cowie CC, Rust KF, Byrd-Holt DD, Gregg EW, Ford ES, et al. (2006) Prevalence of diabetes and impaired fasting glucose in adults in the US population: NHANES survey 1999-2002. Diabetes Care 29: 1263-1268.

8. Kalaria RN, Maestre GE, Arizaga RN, Friedland RP, Galasko D, et al. (2008) Alzheimer's disease and vascular dementia in developing countries: Prevalence, management, and risk factors. Lancet Neurol 7: 812-826.

9. Coresh J, Selvin E, Stevens LA, Manzi J, Kusek JW, et al. (2007) Prevalence of chronic kidney disease in the United States. JAMA 298: 2038-2047. [Crossref]

10. Dagenais S, Garbedian S, Wai EK (2009) Systematic review of the prevalence of radiographic primary hip osteoarthritis. Clin Orthop Relat Res 467: 623-637. [Crossref]

11. Ballou SP, Lozanski FB, Hodder S, Rzewnicki DL, Mion LC, et al. (1996) Quantitative and qualitative alterations of acute-phase proteins in healthy elderly persons. Age Ageing 25: 224-230.

12. Ershler WB, Sun WH, Binkley N, Gravenstein S, Volk MJ, et al. (1993) Interleukin-6 and aging: blood levels and mononuclear cell production increase with advancing age and in vitro production is modi?able by dietary restriction. Lymphokine Cytokine Res 12: $225-230$.

13. Wei J, Xu H, Davies JL, Hemmings GP (1992) Increase of plasma IL-6 concentration with age in healthy subjects. Life Sci 51: 1953-1956. [Crossref]

14. Kabagambe EK, Judd SE, Howard VJ, Zakai NA, Jenny NS, et al. (2011) Inflammation biomarkers and risk of all-cause mortality in the Reasons for Geographic and Racial Differences in Stroke cohort. Am J Epidemiol 174: 284-292. [Crossref]

15. De Martinis M, Franceschi C, Monti D, Ginaldi L (2006) Inflammation markers predicting frailty and mortality in the elderly. Exp Mol Pathol 80: 219-227. [Crossref] 
16. Jensen GL (2008) Inflammation: roles in aging and sarcopenia. JPEN J Parenter Enteral Nutr 32: 656-659. [Crossref]

17. Penninx BW, Kritchevsky SB, Newman AB, Nicklas BJ, Simonsick EM, et 1. (2004) Inflammatory markers and incident mobility limitation in the elderly. J Am Geriatr Soc 52: $1105-1113$.

18. Christian LM, Glaser R, Porter K, Malarkey WB, Beversdorf D, et al. (2011) Poorer self-related health is associated with elevated in?ammatory markers among older adults. Psychoneuroendocrinology 36: 1495-1504.

19. Michaud M, Balardy L, Moulis G, Gaudin C, Peyrot C, et al. (2013) Proin?ammatory cytokines, aging, and age-related diseases. J Am Med Dir Assoc 14: 877-882.

20. Golbidi S, Laher I (2013) Exercise and the aging endothelium. J Diabetes Res 2013: 789607. [Crossref]

21. Bruunsgaard H, Skinhoj P, Qvist J, Pedersen BK (1999) Elderly humans show prolonged in vivo in?ammatory activity during pneumococcal infections. J Infect Dis 180: 551-554.

22. Krabbe KS, Bruunsgaard H, Hansen CM, Møller K, Fonsmark L, et al. (2001) Ageing is associated with a prolonged fever in human endotoxemia. Clin Diagn Lab Immunol 8: $333-338$

23. Wu J, Xia S, Kalionis B, Wan W, Sun T (2014) The role of oxidative stress and inflammation in cardiovascular aging. Biomed Res Int 2014: 615312. [Crossref]

24. Allen SC. Geriatrics. 2017; doi:10.3390/geriatrics2010006 (accessed Jan 14 2019)

25. Barnes PJ (2006) Theophylline for COPD. Thorax 61: 742-744. [Crossref]

26. Culpitt SV, de Matos C, Russell RE, Donnelly LE, Rogers DF, et al. (2002) Effect of theophylline on induced sputum in?ammatory indices and neutrophil chemotaxis in chronic obstructive pulmonary disease. Am J Respir Crit Care Med 165: 1371-1376.

27. Neuner P, Klosner G, Schauer E, Pourmojib M, Macheiner W, et al. (1994) Pentoxyfylline in vivo down-regulates the release of IL-1 beta, IL-6, IL-8 and TNF alpha by human peripheral blood mononuclear cells. Immunology 83: 262-267.

28. Mascali JJ, Cvietusa P, Negri J, Borish L (1996) Anti-inflammatory effects of theophylline: Modulation of cytokine production. Ann Allergy Asthma Immunol 77: 34-38.

29. Ito K, Lim S, Caramori G, Cosio B, Chung KF, et al. (2002) A molecular mechanism of the action of theophylline: Induction of histone deacetylase activity to decrease in?ammatory gene expression. Proc Natl Acad Sci USA 99: 8921-8926.
30. Ichiyami T, Hasegawa S, Matsubara T, Hayashi T, Furukawa S (2001) Theophylline inhibits NF-kappa activation and I kappa B alpha degradation in human pulmonary epithelial cells. Arch Pharmacol 364: 558-561.

31. Scheller J, Chalaris A, Schmidt-Arras D, Rose-John S (2011) The pro- and antiinflammatory properties of the cytokine interleukin-6. Biochim Biophys Acta 1813: 878-888. [Crossref]

32. So B, Kim HJ, Kim J, Song W (2014) Exercise-induced myokines in health and metabolic diseases. Integr Med Res 3: 172-179. [Crossref]

33. Vasunilashorn SM, Ngo L, Inouye SK, Libermann TA, Jones RN, et al. (2015) Cytokines and postoperative delirium in older patients undergoing major elective surgery. J Gerontol A Biol Sci Med Sci 70: 1289-1295.

34. Roubenoff R, Parise H, Payette HA, Abad LW, D'Agostini R, et al. (2003) Cytokines, insulin-like growth factor 1, sarcopenia, and mortality in very old community-dwelling men and women: the Framingham Heart Study. Am J Med 115: 429-435.

35. Stenvinkel P, Ketteler M, Johnson RJ, Lindholm B, Pecoits-Filho R, et al. (2005) IL-10 IL-6 and TNF-alpha: Central factors in the altered cytokine network of uraemia- the good, the bad and the ugly. Kidney Int 67: 1216-1233.

36. Payette H, Roubenoff R, Jacques PF, Dinarello CA, Wilson WF, et al. (2003) Insulinlike growth factor 1 and interleukin 6 predict sarcopenia in very old community-living men and women: the Framingham Heart Study. J Am Geriatr Soc 51: 1237-1243.

37. Spatafora M, Chiappara G, Merendino AM, D'Amico D, Bellia V, et al. (1994) Theophylline suppresses the release of TNF alpha by blood monocytes and alveolar macrophages. Eur Respir J 7: 223-228.

38. Yoshimura T, Usami E, Kurita C, Watanabe S, Nakao T, et al. (1995) Effect of theophylline on the production of IL-1 beta, TNF alpha and IL- 8 by human peripheral blood mononuclear cells. Biol Pharm Bull 18: 1405-1408.

39. Subramanian, Ragulan, Jindal A, Viswambhar V, V AB (2015) The Study of Efficacy, Tolerability and Safety of Theophylline Given Along with Formoterol Plus Budesonide in COPD. J Clin Diagn Res 9: OC10-13. [Crossref]

40. Hancock RE, Nijnik A, Philpott DJ (2012) Modulating immunity as a therapy for bacterial infections. Nat Rev Microbiol 10: 243-254. [Crossref]

41. Shih YN, Chen YT, Seethala R, Aisiko I, Frendl G, et al. (2015) Effect of the use of theophylline and sepsis outcomes. Crit Care Med 43 (Suppl. S1): 274.

Copyright: (C2019 Allen SC. This is an open-access article distributed under the terms of the Creative Commons Attribution License, which permits unrestricted use, distribution, and reproduction in any medium, provided the original author and source are credited. 